\title{
Effect of lower Limbs Rehabilitation on Burn Injured Patients' Outcomes During Emergency Phase
}

\author{
Samia Gamal Ali ${ }^{1}$, Mogedda Mohamed Mohny ${ }^{2}$, Youssef Saleh Hassan $^{3}$ \& Mona Abd Elaziem Ahmed ${ }^{4}$. \\ 1. B.Sc. Nursing, Faculty of Nursing, Assuit General Hospital, Assiut University, Assiut, Egypt. \\ 2. Assistant Professor of critical care and emergency nursing department Faculty of nursing, Assuit University, Egypt. \\ 3. professor of plastic surgery, faculty of medicine, Assiut University, Assiut, Egypt. \\ 4. Lecturer of critical care and emergency nursing department Faculty of nursing, Assuit University
}

\begin{abstract}
Burn rehabilitation is comprehensive, complex and requires a multidisciplinary approach to optimize the patient's physical and psychosocial recovery related to burn. Aim: the study was made to evaluate the effect of lower limb rehabilitation on burn injured patients' outcomes (joint flexibility and muscle strength) during emergency phase. Design: a quasi-experimental design, study design was used to achieve the objectives of the study. Setting: The present study was conducted in burn unit at Assuit general hospital and Assuit university hospital. subjects: purposive sample of 60 adults patients (males and females),they were divided into two equal groups (study and control). Tools: Patient assessment tool, joint flexibility assessment and muscle strength assessment. Results: This study was successed in minimizing muscles contracture to $(6.67 \%)$ of study group versus $(30.00 \%)$ of control group. Conclusion: Implementing the lower limb rehabilitation during emergency phase significantly improved the burn injured patient's outcomes (joint's flexibility and muscles strength) . Recommendation: Rehabilitation exercises should be done as early as possible for patients with burn injury during emergency phase.
\end{abstract}

Keywords: Rehabilitation, Emergency Phase, Joint Flexibility \& Patients' Outcomes.

\section{Introduction}

Burn survivors often suffer from permanent scarring reduced range of motion (ROM), weakness, impaired functional capacity, Psychological and social problems which significantly affect their ability to resume their normal activities post discharge. (Disseldrop et al., 2011)

Healthy lower limb function is essential to performing everyday activities of living (Jette, 2006) Lower limbs are used for standing, all forms of locomotion include recreational, jumping, running, weight lifting and constitute a significant portion of a person's mass.(Shultz, et al., 2008).

Contractures are one of the most common permanent burn squeals. (Jan koller et al., 2014) and is a shortening of the muscle and tendon that leads to deformity and limits joint mobility.(Lewis et al., 2015). Contractures at large joints especially ( hip, knee and ankle) impair functional mobility and activities of daily living(ADL). (Schneider et al., 2006)

Early rehabilitation must begin immediately after the burn has occurred. (Lippincott \& Wilkins, 2014) Rehabilitation of lower limbs includes physical therapy management which includes anti contracture positioning, ROM exercise, stretching, splinting and pressure garments to prevent contracture, minimize the scar formation and to maintain soft tissue length. (Richard et al., 2008).

Range of motion (ROM) is the term that is used to describe the amount of movement at each joint and involves moving a joint through its full range in all appropriate planes. Both passive and active range of motion exercises are initiated from the day of admission. Active(performed by the patient under nursing supervision), assisted(with the nurse helping if the patient cannot do the exercise independently),or passive(performed by the nurse). (Lippincott \& Wilkins, 2014)

Exercises assists in maintaining and building muscle strength, maintaining joint function, preventing deformity, stimulating circulation, developing endurance, and promoting relaxation.

Rehabilitation is a creative, dynamic process that requires a professionals nurses working together with patients and families. The healthy team members represent various disciplines, with each health professional making a unique contribution of the rehabilitation process. Especially nurses, the team may include physicians, nurse practitioners, physical therapists. (Lippincott \& Wilkins, 2014)

The aims of multidisciplinary rehabilitation of a burn include rapid wound closure, preservation of active and passive ROM, prevention of infection, prevention of loss of functional structures and early functional rehabilitation.(Kamolz et al., 2009).

Operation definition of emergency phase of burn injury : The emergent phase begins at the time of the burn injury, usually lasts up to $72 \mathrm{~h}$ from the time the burn occurred, and the time required to resolve the immediate, life threatening problems resulting from 
the burn injury (Lewis et al., 2015).

\section{Significance of the study}

Active rehabilitation is essential to maximize functional outcomes for patients with burn and need to cooperation and coordination between the rehabilitation multidisciplinary team especially the nurse to prevent complications. The urgency and importance of beginning early rehabilitation should be communicated in a clear but gentle manner. Number of burn injured patients who recorded was 210 in 2016year and 233 in 2017 year in burn unit at Assuit General Hospital.

\section{Aim of the study}

To evaluate the effect of lower limb rehabilitation on burn injured patients' outcomes(joint flexibility, muscle strength, reduces contracture and hospital stay) during emergency phase of burn.

Research Hypotheses

- To fulfill the aim of this study the following research hypothesis are formulated:-

- Joint flexibility in the lower limbs of the study group will be better than control group.

- Muscles strength in the lower limbs of the study group will be better than control group.

- The contractures in study group will be less than control group.

\section{Patients \& Method \\ Design}

Quasi experimental research design was used in this study.

\section{Setting}

The study was conducted in burn unit at Assuit General Hospital and University Hospital.

\section{Patients}

Purposive sample of 60 adult(males and females) burn patients aged from(18-60)years old were admitted in the previously mentioned setting with burns in lower limbs and total body surface area (TBSA) ranged from (15to55\%) and thermodynamically stable. The studied patients were divided into two equal 30 patients of each study and control groups.

\section{Exclusion criteria}

patients who met the following criteria were excluded from the study:-

- Patients with Joints diseases such as rheumatoid arthritis

- Burns with fractures or internal injuries

- Patients with severe pain

- Patients with fever(38)or above
Tools of data collection

Three tools were used to collect the data in this study Tool (1): Patient assessment tool:

This tool was developed by the researcher after review of literatures, which used to assess patient condition, and included two parts:

Part(1):Socio demographic and clinical data of burned patients:

Code, age, sex, diagnosis and date of admission, burn causes, depth or degree and total body surface area (TBSA).

\section{Part (2): Hemodynamic data}

This part was used to assess (Pulse, respiration, body temperature, blood pressure).

Tool (2):" Joint flexibility assessment tool"

This tool was adopted from (Wagner et al.,2010), after reviewing related literature and used to assess flexibility of three major joints (hip, knee and ankle) by the goniometer for both (study and control)groups to measure the angles of joints in degrees which scored by the patient with movements not ranged .

Goniometer is an instrument used to measure angles of

Hip: Flexion:0-120 degree,Extension:030degree,Abduction:0-45degree,

Adduction: 40-45degree, Internal rotation: 040degree and External rotation: 0-45degree

Knee: Flexion:0-135degree, Extension: 0-15degree and Internal rotation: 0-10degree.

Ankle :Dorsiflexion: 0-20 degree and Planter flexion: 0-50degree

Tool (3): Muscle strength assessment tool:

This tool was adopted from (Hermans et al., 2012), by Medical Research Council (MRC), used to assess muscle strength of lower limbs for both (study and control)groups, which consisted of a six points.

This score was grading from $(0-5)$.

1. No contraction visible or palpable (0)

2. Flicker of contraction visible or palpable, no visible movement (1)

3. Movement but only with gravity eliminated over almost full ROM(2)

4. Movement against gravity over almost full ROM without resistance (3)

5. Movement against moderate resistance over full $\mathrm{ROM}(4)$

6. Normal power(5)

Method

The study was conducted throughout three phases:-

\section{1- Preparatory phase}

1. Permission to conduct the study was obtained from the responsible authorities of burn unit after explanation of the aim and nature of the study 
2. the data collection tools were developed by the researcher based on the reviewing relevant literature

3. Content validity of the developed tools was done by seven experts((2) for medical,(2) for physiotherapy and (3) for nursing) in the related fields and the necessary modifications was done accordingly.

4. A pilot study carried out in order to assess the feasibility and applicability of the tools and the necessary modifications were done. The pilot study was done on $\mathbf{6}$ patients were included to the study.

5. Reliability of tools was done using Chronbach's coefficient alpha score; it was 0.815 for tool one.

\section{Ethical Considerations}

Research was approved from ethical committee in the faculty of nursing. There is no risk for study subjects during application of the research. The study was followed common ethical principles in clinical research.

\section{Implementation phase}

The data were collected in ten months from(July 2018to April 2019) For both(study and control) groups; the researcher assessed the patient's socio demographic and clinical data about burn injury in the first day of admission from the patient or the family and his or her sheet using tool one ( part 1).

The researcher assessed joint's range of motion(joint flexibility) for major joints of lower limbs (hip, knee and ankle) by (tool two), and assessed the muscles strength by( tool three) in the first day of admission ,after week and at the discharge .

For study group: The patients received the rehabilitation program by the researcher in the following manner: Consult the practitioner or physical therapist about limitations or precautions. Determine the joints that need range of motion exercises. the researcher assessed the vital signs three times (before, during and after) $1^{\text {st }}$ session of physiotherapy to be Sure the patient's hemodynamic state is stable. Physiotherapy includes anti contracture positioning, ROM exercise, stretching, splinting and pressure garments .The researcher applied the range of motion exercises on patient's joints slowly, in gently manner and to the end of the normal ROM or to the point of pain, but no further. Active range of motion (AROM) exercises were performed by the patient and for patients with burns percentage about(15to35\%).Assistive \& passive range of motion exercises were performed by the patient with researcher assistance for patients with burns percentage about (40to55\%). Patient's positions whom with lower limbs burns, hip joint movements(flexion, extension ,abduction, adduction, internal rotation and external rotation)the patient was in the (supine and prone position).knee joint movements (flexion, extension and internal rotation) and ankle joint movements(dorsiflexion and planter flexion) the patient was in the(prone and sitting)position. All the previous movements was performed as early as possible after patient's hemodynamic state stability three times daily by three sessions, five movements in every session to the joint in the affected place through (abduction, adduction, flexion, extension, internal rotation ,external rotation, dorsiflexion and planter flexion) with increasing the number of movements every day five movements for $1^{\text {st }}$ week of admission, after week the patients continued the physiotherapy by group of nurses(who were trained on rehabilitation program).

For Control group: patients received the hospital routine care(range of motion exercises once daily, day per day after emergency phase of burn ending or in the ( six or seven)day after burn injury .

3. Evaluation phase:

Every patient of both( study and control) groups was evaluated three times by using tool (one, two and three) before initiation of rehabilitation exercises, after one week and at the discharge to evaluate the effect of lower limb rehabilitation on patients' outcomes.

\section{Statistical analysis}

The data were tested for normality using the Anderson-Darling test and for homogeneity variances prior to further statistical analysis. Categorical variables were described by number and percent $(\mathrm{N}$, $\%)$, where continuous variables described by mean and standard deviation (Mean, SD). Chi-square test and fisher exact test used to compare between categorical variables where compare between continuous variables by t-test land anova test . A two-tailed $\mathrm{p}<0.05$ was considered statistically significant. All analyses were performed with the IBM SPSS 20.0 software . 


\section{Result}

Table (1): distribution of (Study and Control) groups According to socio demographic and medical data.

\begin{tabular}{|c|c|c|c|c|c|}
\hline & \multicolumn{2}{|c|}{ Study $(n=30)$} & \multicolumn{2}{|c|}{ Control $(n=30)$} & \multirow{2}{*}{ P.value } \\
\hline & No. & $\%$ & No. & $\%$ & \\
\hline \multicolumn{6}{|c|}{ Age group by year } \\
\hline from 18 to $<25 \mathrm{y}$ & 19 & 63.3 & 18 & 60.0 & \multirow{3}{*}{0.933} \\
\hline from 25 to $<35 \mathrm{y}$ & 4 & 13.3 & 5 & 16.7 & \\
\hline More than 35y & 7 & 23.3 & 7 & 23.3 & \\
\hline Mean \pm SD & \multicolumn{2}{|c|}{$27.35 \pm 9.66$} & \multicolumn{2}{|c|}{$26.35 \pm 7.88$} & 0.664 \\
\hline \multicolumn{6}{|l|}{ Sex } \\
\hline Male & 23 & 76.7 & 16 & 53.3 & \multirow{2}{*}{0.058} \\
\hline Female & 7 & 23.3 & 14 & 46.7 & \\
\hline Length of stay & \multicolumn{2}{|c|}{$16.2 \pm 3.85$} & \multicolumn{2}{|c|}{$19.67 \pm 3.63$} & $0.001 * *$ \\
\hline \multicolumn{6}{|l|}{ Diagnosis } \\
\hline scald burn & 15 & 50.0 & 15 & 50.0 & \multirow{3}{*}{1.000} \\
\hline Electrical & 2 & 6.7 & 2 & 6.7 & \\
\hline fire burn & 13 & 43.3 & 13 & 43.3 & \\
\hline \multicolumn{6}{|l|}{ Degree } \\
\hline $2^{\text {nd }}$ & 3 & 10.0 & 0 & 0.0 & \multirow{2}{*}{0.076} \\
\hline Mixed & 27 & 90.0 & 30 & 100.0 & \\
\hline \multicolumn{6}{|l|}{ Place of burn } \\
\hline Hip & 2 & 6.67 & 2 & 6.67 & 0.604 \\
\hline Knee & 19 & 63.33 & 18 & 60.00 & 0.999 \\
\hline Ankle & 17 & 56.67 & 15 & 50.00 & 0.795 \\
\hline TBSA & \multicolumn{2}{|c|}{$29.17 \pm 11.3$} & \multicolumn{2}{|c|}{$29.83 \pm 11.48$} & 0.822 \\
\hline
\end{tabular}

Chi-square test

* Statistically significant difference $(p<0.05)$

Independent $T$ - test $\quad * *$ statistically significant difference $(p<0.01)$.

\# more than one answer.

Number of study sample :(30) for each study and control groups.

Number of joints which affected :(38) for study group and (35) for control group.

Table (2) : the mean distribution of hemodynamic status(vital signs) at first session (Before, During, After) exercises of Study group.

\begin{tabular}{|c|c|c|c|c|}
\hline & \multicolumn{4}{|c|}{ Study $(n=30)$} \\
\hline & Before & During & After & \multirow{2}{*}{ P.value } \\
\hline & Mean \pm SD & Mean \pm SD & Mean \pm SD & \\
\hline \multicolumn{5}{|l|}{ on admission } \\
\hline Body Temperature & $36.44 \pm 0.38$ & $36.47 \pm 0.42$ & $36.47 \pm 0.42$ & $<0.001 * *$ \\
\hline Pulse & $79.67 \pm 3.86$ & $82.27 \pm 3.54$ & $82.27 \pm 3.54$ & $0.007 * *$ \\
\hline Respiration & $22.23 \pm 1.57$ & $19.23 \pm 1.76$ & $19.23 \pm 1.76$ & $<0.001 * *$ \\
\hline Systolic blood pressure & $103.17 \pm 4.04$ & $103.73 \pm 3.96$ & $103.73 \pm 3.96$ & $<0.001 * *$ \\
\hline Diastolic blood pressure & $63.33 \pm 3.3$ & $64 \pm 4.43$ & $64 \pm 4.43$ & $<0.001 * *$ \\
\hline
\end{tabular}

One Way ANOVA** statistically significant difference ( $p<0.01)$.

Number of rehabilitation program(ROM exercises) session: (3)session daily, we assessed the hemodynamic stability state(vital signs) in the first session of program (Before, During, After) exercises for Study group. 
Table (3) :- Comparison between study and control groups regarding to joint flexibility of lower limbs (before, After $1^{\text {st }}$ week and At discharge).

\begin{tabular}{|c|c|c|c|c|c|c|c|c|c|}
\hline \multirow{2}{*}{ Hip } & \multicolumn{3}{|c|}{ before } & \multicolumn{3}{|c|}{ After $1^{\text {st }}$ week } & \multicolumn{3}{|c|}{ At the discharge } \\
\hline & Study & Control & P. value & Study & Control & P. value & Study & Control & P. value \\
\hline Flexion & $102.75 \pm 7.42$ & $100 \pm 0$ & 0.653 & $108.75 \pm 4.6$ & $103.5 \pm 0.71$ & 0.251 & $112.75 \pm 3.18$ & $106.5 \pm 0.71$ & 0.113 \\
\hline xtension & $28 \pm 2.83$ & $17.5 \pm 3.54$ & 0.082 & $30 \pm 0$ & $26.25 \pm 11.67$ & 0.694 & $30 \pm 0$ & $23.5 \pm 3.54$ & 0.122 \\
\hline Abduction & $40.25 \pm 0.35$ & $36.5 \pm 2.12$ & 0.133 & $45 \pm 1.41$ & $40.5 \pm 2.12$ & 0.130 & $47 \pm 0$ & $42.5 \pm 0.71$ & $0.012 *$ \\
\hline Adduction & $16.5 \pm 0.71$ & $14.5 \pm 0.71$ & 0.106 & $20.5 \pm 0.71$ & $18 \pm 0$ & $0.038^{*}$ & $22.5 \pm 0.71$ & $19 \pm 0$ & $0.020^{*}$ \\
\hline $\begin{array}{l}\text { Internal } \\
\text { Rotation }\end{array}$ & $35.5 \pm 0.71$ & $30 \pm 0$ & $0.008 * *$ & $39 \pm 0$ & $33.5 \pm 0.71$ & $0.008^{* *}$ & $40 \pm 0$ & $36 \pm 1.41$ & 0.057 \\
\hline $\begin{array}{l}\text { External } \\
\text { Rotation }\end{array}$ & $38 \pm 2.83$ & $35.5 \pm 2.12$ & 0.423 & $43 \pm 1.41$ & $39 \pm 1.41$ & 0.106 & $45 \pm 0$ & $42 \pm 0$ & \\
\hline \multicolumn{10}{|l|}{ Knee } \\
\hline Flexion & $120.63 \pm 2.88$ & $119.33 \pm 2.99$ & 0.187 & $126.13 \pm 2.28$ & $122.94 \pm 3.37$ & $0.002 * *$ & $129.63 \pm 1.61$ & $124.64 \pm 3.44$ & $<0.001 * *$ \\
\hline xtension & $10.11 \pm 1.44$ & $7.33 \pm 2.14$ & $<0.001 * *$ & $13.92 \pm 1.42$ & $10.31 \pm 2.19$ & $<0.001 * *$ & $14.68 \pm 1.38$ & $11.56 \pm 2.43$ & $<0.001^{* * *}$ \\
\hline $\begin{array}{l}\text { Internal } \\
\text { Rotation }\end{array}$ & $6.92 \pm 1.4$ & $5.39 \pm 1.04$ & $0.001 * *$ & $9.42 \pm 0.61$ & $8.11 \pm 0.76$ & $<0.001 * *$ & $10 \pm 0$ & $8.61 \pm 0.61$ & $<0.001 * *$ \\
\hline \multicolumn{10}{|l|}{ Ankle } \\
\hline $\begin{array}{l}\text { Planter } \\
\text { Flexion }\end{array}$ & $38.32 \pm 4.67$ & $35.2 \pm 2.91$ & $0.033^{*}$ & $43.12 \pm 2.91$ & $39.27 \pm 2.31$ & $<0.001 * *$ & $45 \pm 0$ & $41.67 \pm 1.45$ & $<0.001 * *$ \\
\hline $\begin{array}{l}\text { Drosi } \\
\text { Flexion }\end{array}$ & $15.18 \pm 2.51$ & $12.2 \pm 3.36$ & $0.008^{* *}$ & $18.59 \pm 1.58$ & $15.43 \pm 2.96$ & $0.001 * *$ & $20 \pm 0$ & $16.87 \pm 2.19$ & $<0.001 * *$ \\
\hline
\end{tabular}

Independent T-test $*$ statistically significant difference $p<0.05$, ** statistically significant difference $p<0.01$

The scoring system is not presented because in this study we measure the degree of joints' angles of the patient such as in hip flexion (110tol30), not ranged mild, moderate and sever.

Table (4): Assessment of Study and control groups according to Muscle Strength of lower limbs (before range of motion, after $1^{\text {st }}$ week and at the discharge).

\begin{tabular}{|c|c|c|c|c|c|c|}
\hline \multirow[b]{3}{*}{ Joints which affected } & \multicolumn{3}{|c|}{ Study } & \multirow[b]{3}{*}{ Hip } & \multicolumn{2}{|c|}{ Control } \\
\hline & \multicolumn{3}{|c|}{ No \% } & & \multicolumn{2}{|c|}{ No\% } \\
\hline & Hip & knee & Ankle & & Knee & Ankle \\
\hline \multicolumn{7}{|l|}{ Before ROM } \\
\hline 0 (No contraction visible or palpable) & - & - & & - & - & \\
\hline 1(Flicker of contraction visible or palpable, no visible movement) & - & & - & - & & - \\
\hline \multirow[t]{2}{*}{ 2(Movement but only with gravity eliminated over almost full ROM) } & 2 & 19 & 17 & 2 & 18 & 15 \\
\hline & $100 \%$ & $100 \%$ & $100 \%$ & $100 \%$ & $100 \%$ & $100 \%$ \\
\hline 3(Movement against gravity over almost full ROM without resistance) & - & - & & - & - & \\
\hline 4(Movement against moderate resistance over full ROM) & - & - & & - & - & \\
\hline 5(Normal power) & - & - & & - & - & \\
\hline \multicolumn{7}{|l|}{ After $1^{\text {st }}$ week } \\
\hline \multicolumn{7}{|l|}{ 0(No contraction visible or palpable) } \\
\hline \multirow[t]{2}{*}{1 (Flicker of contraction visible or palpable, no visible movement) } & 0 & 2 & 2 & 0 & 7 & 7 \\
\hline & & $10.5 \%$ & $11.8 \%$ & & $38.9 \%$ & $46.7 \%$ \\
\hline \multirow[t]{2}{*}{ 2(Movement but only with gravity eliminated over almost full ROM) } & & & & & 1 & 1 \\
\hline & & & & & $5.6 \%$ & $6.7 \%$ \\
\hline \multirow[t]{2}{*}{ 3(Movement against gravity over almost full ROM without resistance) } & & & & 2 & 10 & 7 \\
\hline & & & & $100 \%$ & $55.6 \%$ & $46.7 \%$ \\
\hline \multirow[t]{2}{*}{ 4(Movement against moderate resistance over full ROM) } & 2 & 17 & 15 & & & \\
\hline & $100 \%$ & $89.5 \%$ & $88.2 \%$ & & & \\
\hline \multicolumn{7}{|l|}{ 5(Normal power) } \\
\hline At the discharge & Hip & knee & ankle & hip & knee & Ankle \\
\hline \multicolumn{7}{|l|}{ 0 No contraction visible or palpable) } \\
\hline \multirow[t]{2}{*}{ 1(Flicker of contraction visible or palpable, no visible movement) } & & 2 & 2 & & 7 & 7 \\
\hline & & $10.5 \%$ & $11.8 \%$ & & $38.9 \%$ & $46.7 \%$ \\
\hline
\end{tabular}




\begin{tabular}{|c|c|c|c|c|c|c|}
\hline \multirow{2}{*}{ Lower limbs } & \multicolumn{3}{|c|}{ Study } & & \multicolumn{2}{|c|}{ Control } \\
\hline & \multicolumn{3}{|c|}{ No \% } & & \multicolumn{2}{|c|}{ No\% } \\
\hline \multirow[t]{2}{*}{ 2(Movement but only with gravity eliminated over almost full ROM) } & & & & & 1 & 1 \\
\hline & & & & & $5.6 \%$ & $6.7 \%$ \\
\hline \multirow[t]{2}{*}{ 3(Movement against gravity over almost full ROM without resistance) } & & & & 2 & 10 & 7 \\
\hline & & & & $100 \%$ & $55.6 \%$ & $46.7 \%$ \\
\hline \multirow[t]{2}{*}{ 4(Movement against moderate resistance over full ROM) } & & 5 & 6 & & & \\
\hline & & $26.3 \%$ & $35.3 \%$ & & & \\
\hline \multirow[t]{2}{*}{ 5(Normal power) } & 2 & 12 & 9 & & & \\
\hline & $100 \%$ & $63.2 \%$ & $52.9 \%$ & & & \\
\hline
\end{tabular}

Number of joints that affected:(38)for study group and(35)for control group.

Number of hip joint: (2)for study group and(2)for control group.

Number of knee joint: (19)for study group and(18)for control group.

Number of ankle joint: (17)for study group and(15)for control group.

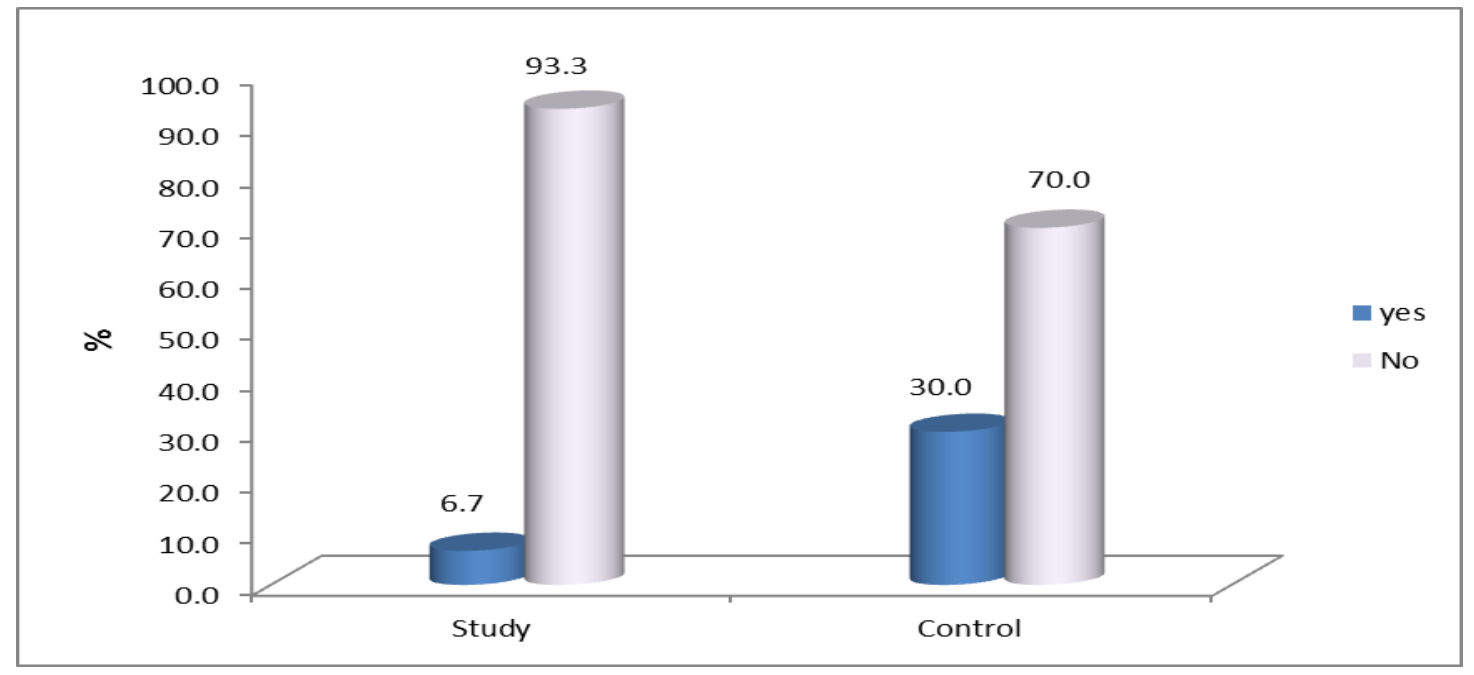

Figure(1): muscle contractures of study and control group

The muscle contractures were evaluated by muscle strength assessment test (tool 3).

Table (1): This table show the socio demographic and medical data of Study and Control groups. Related to age, the mean age in study and control groups(27.35 \pm 9.66 and $26.35 \pm 7.88)$ respectively. Regarding to gender, just under three quarters of patients were males in study group and the male patients were more than females in control group $(76.7 \%$ and $53.3 \%)$ respectively. Related to occupation ,the study group patients were (13.3\%) employed and (86.7\%)were non-employed and $(100.0 \%)$ were non-employed of patients in control group. According to length of stay, mean length of stay was(16.2 \pm 3.85$)$ for study group and $(19.67 \pm 3.63)$ for control group, As regard diagnosis show that $(50.0 \%)$ were scald burns while $(6.7 \%)$ were electrical burns and(43.3\%) were fire burns of patients in study and control groups.

Table(2):it shows hemodynamic status of study groups before, during and after ROM exercises on admission. Regarding to body temperature ,pulse, respiration and blood pressure not affected by range of motion exercises.

Table (3): This table illustrates statistically significant differences of joints flexibility (before range of motion), after1st week and at the discharge, Regarding to hip (abduction and adduction ) of the study group $(\mathrm{p}<0.012)$ and $(\mathrm{p}<0.020)$, Related to knee(flexion, extension and internal rotation)) statistically significant differences were founded $(\mathrm{p}<0.001)$. According to ankle (planter flexion and Dorsiflexion ) statistically significant differences were founded $(p<0.001)$ of study group and control group.

Table (4): This table shows that there was improvement of muscles strengthen of study group more than control groups. Regarding to before range of motion, (100\%) of study and control groups that with hip, knee and ankle burns take grade( 2) of 
(MRC) scale, According to after $1^{\text {st }}$ week, $(89.5 \%)$ patients with knee burns and (88.2\%)patient with ankle burns of study group take grade (4) but (55.6\%) patients with knee burns and (46.7\%) patients with ankle burns of control group take grade (3). Related to at the discharge, $(63.2 \%)$ patients with knee burns and $(52.9 \%)$ patients with ankle burns of study group take grade (5) while $(55.6 \%)$ patients with knee burns and $(46.7 \%)$ patients with ankle burns of control group take grade (3).

Figure (1): This figure shows that ( $93.33 \%$ ) of study group not affected with muscle contracture and $(6.67 \%)$ were affected with muscle contracture. According to muscle contracture of control group, $(30.00 \%)$ were affected with muscle contracture and $(70.00 \%)$ not affected with muscle contracture.

\section{Discussion}

Many of these patients require surgical interventions, extensive pain control, immobilization and rehabilitation. Patients with burns have particularly prolonged lengths of hospital stay. (Singer et al., 2019).

Advances in burn care in recent decades have resulted in a growing population of burn survivors and an increased need for inpatient rehabilitation. Burn survivors who require inpatient rehabilitation typically experience severe and complicated injuries. (Kornhaber et al., 2019).

The aim of this study was to evaluate the effect of lower limb rehabilitation on burn injured patients' outcomes (joint flexibility, muscle strength, reduces contracture and hospital stay).

This discussion will cover the main result findings as follow

Regarding to Socio demographic and medical data

The present study showed that; more than half of studied burned patients age ranged from 18 to 25 years old with mean age study and control groups, this was in the same line with Rebarczyk et al., (2017) who found more than half of these victims were of the age group 21-25 years. But dis agreed with this study and found that married female victims far outnumbered unmarried females, their ratio being 5.9: 1. In this respect Maritz et al., (2012) found that the majority of burned patients were ranged 20-40 years old. This was different with study of Lee et al., (2016) in a study entitled "A single institution retrospective review of incidence, etiology, and outcomes in 2273 burn patients" and found that the major number of burned patients were males. In addition, those result was not in the same line with Anlatıcı et al., (2017) who originated that there was a preponderance of female victims in their study. The vast majority of female adults were housewives, and most of the men were employed outside the home.

As regard the cause of burn, more than half of them was scaled that were in the same line with Wood et al., (2010) who mentioned in their study that from the analysis, observe that the most common mechanism causing burn injury in both sexes is scald.

Overall scalds account for nearly third of the total population admitted. mean length of stay $16.2 \pm 3.85$ and $19.67 \pm 3.63$, with mixed degree of burn, knee was the main site of burn, this agreed with the result of MacDessi et al., (2019).

Burn patients referred for inpatient rehabilitation are either older or have large total percentage of area (TBSA) burns. All patients made significant functional improvements and consequently inpatient rehabilitation can be considered an important component of care after a burn injury. Sliwa et al., (2005).

\section{According to Hemodynamic status}

The present study found that; there were significant difference between the 3 phases (Before, During, After) application of rehabilitation according to vital signs of study group either on admission. In addition, the data showed that studied burned patients mean body temperature, increase to normal level after a week of burn after rehabilitation program implementation. Regarding pulse, respiration and blood pressure mean level were within normal range during the first week of burn. The results of present study showed that the patient's hemodynamic state was not affected after implementation of early rehabilitation and most of the patients were oriented, nearly half had no fever, hypothermia, tachycardia or bradycardia, tachypnea ,hypotension or hypertension. Regarding to Joint flexibility

The result of this study revealed that Joint Flexibility (before, After) $1^{\text {st }}$ week and At discharge of burn in lower limbs for study and control groups there were significant deference in all ROM .In my opinion, the improvement of joint's flexibility occurred related to starting and applying ROM exercises early, in the emergency phase of burn before the healing process beginning because after the healing the contractures occurred and the movement became difficult and painful.

These findings were consistent with Snowdon et al., (2018) who found that linear measures of functional status, showed significant improvements from admission to discharge for all patients. In addition, all patients made significant functional improvements and consequently inpatient rehabilitation can be considered an important component of care after a burn injury. 
After burn, the knee joint loses flexibility, and the muscles around the joints and in the muscles tend to atrophy, so rehabilitation is required in order to strengthen the surrounding muscles and stabilize the joint. All treatment options require extensive physical therapy to regain muscle strength and flexibility around the knee and restore (ROM). Villafañe et al., (2019)

In this respect, Schneider et al., (2012) found that subjects demonstrate significant improvements in ROM and balance from admission to discharge $(\mathrm{p}<0.05)$.

\section{Related to Muscle strength}

In the existing study, there was improvement regarding the comparison between muscle strength assessment (before, after1st week and At discharge) for study and control groups. In addition, the study showed that the knee was the main joint in the lower extremities where the level of muscle strength improved after ROM. The application of these finding might also have important effect on muscles strength because this strengthen impact of the daily activities, limits the movements and all this lead to muscle's weakness and loss of function.

Thus, Esselman, (2007) illustrated in this line that burn injuries result in significant physical and psychological complications that require comprehensive rehabilitation treatment and coordination with the acute care burn team. This interdisciplinary rehabilitation treatment is focused on preventing long-term problems with scarring, contractures, and other problems that limit physical function.

In this respect, Porter et al., (2015) reviewed that the evidence for the utility of rehabilitative exercise training in restoring physiological function in burn survivors.In addition, Lippincott \& Wilkins, (2014) concentrated that Exercises rehabilitation help in maintaining and building muscle strength, maintaining joint function, preventing deformity, stimulating circulation, developing endurance, and promoting relaxation

Rehabilitation has been considered one of the key factors for regaining muscle strength and neuromuscular control to return to activities of daily living and sporting activities after injury and surgery. Muscles weakness and impaired neuromuscular control of the lower extremity are the main functional impairments in those who burn injury. Hopkins et al., (2016).

\section{Complication}

The present study showed that the muscles contracture was minimized in study group versus control group. In my opinion the rehabilitation exercises had an effect on the patients, improving the comprehensive health and general health condition of patients with burns and minimizing muscles weakness which lead to muscles contracture. This results was in the same line with Mehta et al., (2019) who mentioned that therapy mainly focused on preventing complication or decreasing its incidence to occur as scarring, contractures, and other complications which effect on the patients' function. In the opposite side Kang et al., (2018) found that the presence of complications can't be affected by the physiotherapy treatment but the surgery early excision mainly make changes and control the complications mainly contracture, however massage or ROM decrease itching decrease pain but not contracture.

The aim of burn Rehabilitation are to minimize the adverse effects caused by the injury in terms of maintaining range of movement, minimizing contracture development and impact of scaring and minimizing functional ability. Procter, (2010).

Post burn contractures are perhaps the most dreaded and distressing morbidity in patients surviving major burns. Rapid and immediate rehabilitation make it easy to the patients return to be functionally early.

Richard et al., (2009). Out comes

The present study revealed that there were a statistical significant differences between study and control group ,primary outcome study group stayed less than control group and may be lead to decreasing the risk of infection,. secondary outcome joint's flexibility and muscle's strength which make the movement and that improved after ROM exercises applying to maximize the functions of the patient's life and work. Thirdly, prevention of muscles contractures occurrence which lead to loss of function . Finally, starting the rehabilitation (ROM exercises) of burn patient early, in the first day of admission increase and improves the joint's flexibility, muscle's strength and to prevent muscle contracture that lead to loss of function.

\section{Conclusion}

In the light of the current study, it can be concluded that implementing rehabilitation exercises of lower limb burn injured patients in the first day of admission during emergency phase improve joints flexibility, muscles strength and minimizing muscles contracture.

\section{Recommendation}

Based on the result of present study, following recommendations are suggested: 
- Range of motion exercises should be done as early as possible after burn injury in burn unit.

- Equip burns unit with simple illustrated nursing guideline about rehabilitation of burned patients.

- Reapplication of the study on a large probability of sample from different burn unit is required for generalization.

\section{References}

1. Anlatıcı, R., Özerdem,Ö., Dalay, C., Kesiktaş, E., Seydaoğlu, G., (2017): A retrospective analysis of 1083 Turkish patients with serious burns. Burns, 28(3), 231-237 .

2. Disseldorp, L., Nieuwenhuis, M., Van Baar, M., \& Mouton, L., (2011): physical fitness in people after burn injury: A systematic review', Arch Phys Med Rehabil 92, 15011509.

3. Esselman, P., (2007): Burn rehabilitation: an overview. Archives of physical medicine and rehabilitation, 88(12), S3-S6.

4. Villafañe, J., Bishop, M., Pedersini, P., \& Berjano, P., (2019): Physical activity and osteoarthritis: update and perspectives. Pain Medicine, Volume 20, Issue 8, August 2019, Pages 1461-1463

5. Hermans G., Clerck X., Vanhullebusch T., (2012): Interobserver agreement of medical research council sum-score and handgrip strength in the intensive care unit. Muscle nerve;45:18-25.

6. Hopkins, R., Mitchell, L., Thomsen, G., Schafer, M., Link, M., \& Brown, S., (2016): Implementing a mobility program to minimize post-intensive care syndrome. AACN Adv Crit Care, 27(2), 187-203.

7. Jan K., (2014): Text Book For Sudents Of General Medicine And dentistry, ISBN 978-80 223-3576-8,P5.

8. Jette, A., (2006): Toward a Common language for Function,

9. Disability and Health. Physical Therapy, 86, 726-734.

10. Kamolz, L., Kitzinger, H., Karle, B., \& Frey, M., (2009): The treatment of hand burns', Burns, 35(3), 327-337.

11. Kang, S., Kufta, K., Sollecito, T., \& Panchal, N., (2018): A treatment algorithm for the management of intraoral burns: A narrative review. Burns, 44(5), 1065-1076.

12. 11-Knighton, J., \& Jako, M., (2012): Nursing management of the burn-injured person. In Handbook of Burns (pp. 387-430). Springer, Vienna.
13. Kornhaber, R., Rickard, G., McLean, L., Wiechula, R., Lopez, V., \& Cleary, M., (2019): Burn care and rehabilitation in Australia:

health professionals' perspectives. Disability and rehabilitation, 41(6), 714-719.

14. Lee, C., Mahendraraj, K., Houng, A., Marano, M., Petrone, S., Lee, R., \& Chamberlain, R., (2016): A single institution retrospective review of incidence, etiology, and outcomes in 2273 burn patients (19952013). Journal of Burn Care \& Research, 37(6), e579-e585.

15. Lewis, Dirksen, Heitkemper, Bucher, Chintamani, \& Mringlinimani, (2015): Medical surgical nursing, 2nd south asia ed, chapter 25, p. 475.

16. Lippincott W., \& Wilkins, (2014): integumentary function, Text book of medical Surgical nursing, $13^{\text {th }}$ ed, chapter10,p153-1829.

17. MacDessi, S., Bhimani, A., Burns, A., Chen, D., Leong, K., Molnar, R. , \& Wood, J., (2019): Does soft tissue balancing using intraoperative pressure sensors improve clinical outcomes in total knee arthroplasty? A protocol of a multicenter and omised controlled trial. BMJ open, 9(5), e027812.

18. Maritz, D., Wallis, L., Van Der Merwe, E., \& Nel, D., (2012): The etiology of adult burns in the Western Cape, South Africa. Burns, 38(1),P.P. 120-127.

19. Mehta, M. A., Ranjan, V., Kulkarni, A. K., \& Sarwade, P., (2019): linicoepidemiological study of post burn contractures at a tertiary care centre in western India. International Surgery Journal, 6(6), 1896-1900.

20. Porter, C., Hardee, J., Herndon, D., \& Suman, O., (2015): The role of exercise in the rehabilitation of patients with severe burns. Exercise and sport sciences reviews, 43(1), 34.

21. 2Procter, F., (2010): Rehabilitation of the burn patient. Indian journal of plastic surgery: official publication of the Association of Plastic Surgeons of India, 43(Suppl), S101.

22. Rebarczyk M., Schafer J., EIm C., Sarvepalli S., Vaswani P., Balhara S., Carlson L., \& Jacquet G., (2017): A systemic review of burn injuries in low and middle income countries: Epidemiology in WHO defined Afrecianregion, African Journal of Emergency Medicine 7, P.P. 30-37.

23. Richard R., Hedman T., Quick C., (2008): A Clarion to recommit and raffirm burn rehabilitation. J Burn Care Res;29:425-32. 
24. Richard, R., Baryza, M., Carr, J., Dewey, W., Dougherty, M., Forbes-Duchart, L., \& Moore, M., (2009): Burn rehabilitation and research: proceedings of a consensus summit. Journal of Burn Care \& Research, 30(4), 543-573.

25. Schneider J., Holavanahali R., Helm P., Goldstein R., \& Kowalske K., (2006): Contractures in burn injury: defining the problem. J Burn Care Res; 27(4):508-4.

26. Schneider, J., Qu, H., Lowry, J., Walker, J., Vitale, E., \& Zona, M., (2012): Efficacy of inpatient burn rehabilitation: a prospective pilot study examining range of motion, hand function and balance. Burns, 38(2), 164-171.

27. Shultz S., Nguyen A., \& Schmitz R., (2008): "Differences in lower extremity anatomical and postural characteristics in males and females between maturation groups". J Orthop Sports Phys Ther. 38(3):137-49.

28. Singer, P., Blaser, A., Berger, M., Alhazzani, W., Calder, P., Casaer, M., \& Preiser, J., (2019): ESPEN guideline on clinical nutrition in the intensive carunit.Clinicalnutrition,38(1), 48- 79.

29. Sliwa J., Heinemann A., \& Semik P., (2005): Inpatient Rehabilitation Following Burn Injury: Patient Demographics and Functional Outcomes, Archives of Physical Medicine and Rehabilitation, Volume 86, Issue 10, P.P. 19201923.

30. Snowdon, D., Leggat, S., Harding, K., Boyd, J., Scroggie, G., \& Taylor, N., (2018): The association between effectiveness of clinical supervision of allied health professionals and improvement in patient function in an inpatient rehabilitation setting. Disability and rehabilitation, P.P. 1-10.

31. Wagner L., \& Clevenger C., (2010): Contractures in nursing home resident, JAMDA, 11(2):94:9.

32. Wood S., Bellis M., \& Atherton J., (2010): Burns: a review of evidence for prevention from the UK focal point for violence and injury prevention, P.P. 34:56 